\title{
O OLHAR PASSAGEIRO: UMA EXPERIÊNCIA DE INTERVENÇÃO URBANA E APROPRIAÇÃO DO ESPAÇO PÚBLICO.
}

Paula Biazus

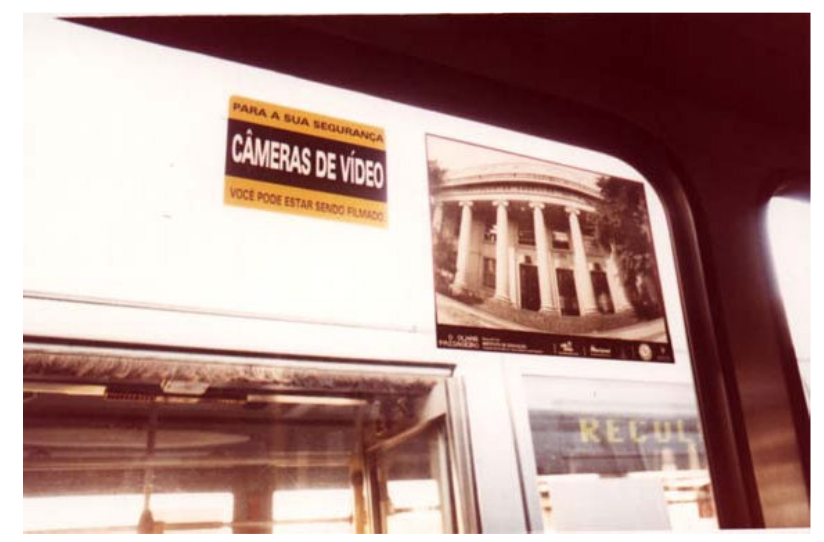

\section{Construindo um Olhar Passageiro}

O objeto desse trabalho consiste na análise de uma experiência de produção cultural enquanto intervenção urbana no espaço da cidade de Porto Alegre. Trata-se de um projeto chamado O Olhar Passageiro executado, durante o ano de 2003, por cinco fotógrafos que utilizam uma técnica diferenciada para obtenção de imagens, a fotografia pinhole. É importante ressaltar o lugar de onde parto para uma análise etnográfica como integrante deste grupo, denominado Lata Mágica, desde a sua formação em 1999. Pressuposto fundamental para a construção metodológica dessa narrativa que pretende inserir essa série de imagens produzidas sobre a cidade de Porto Alegre e fixadas nas janelas internas dos seus ônibus metropolitanos em um contexto de políticas culturais que possibilitam e negociam essas iniciativas com a preservação do patrimônio cultural

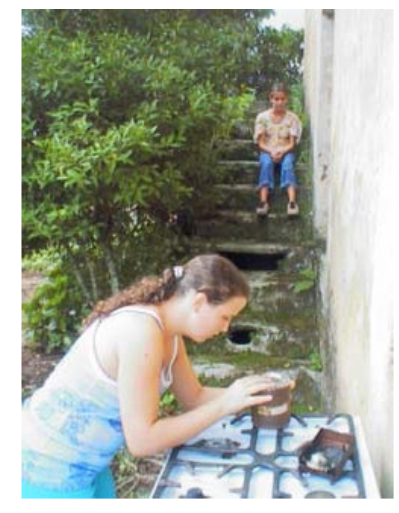
e, conseqüentemente, com a constituição da cidade. Coloco-me em uma postura etnográfica de reflexão sobre uma experiência vivida como fotógrafa na tentativa de transformar esse tempo precedente (tempo vivido) em uma construção narrativa, u ma experiência temporal configurada, conforme Paul Ricoeur (1994), sob m ponto de vista antropológico.

A fotografia pinhole consiste na utilização de câmeras sem lentes, que através do princípio da câmara escura, permite a obtenção de imagens de uma maneira 


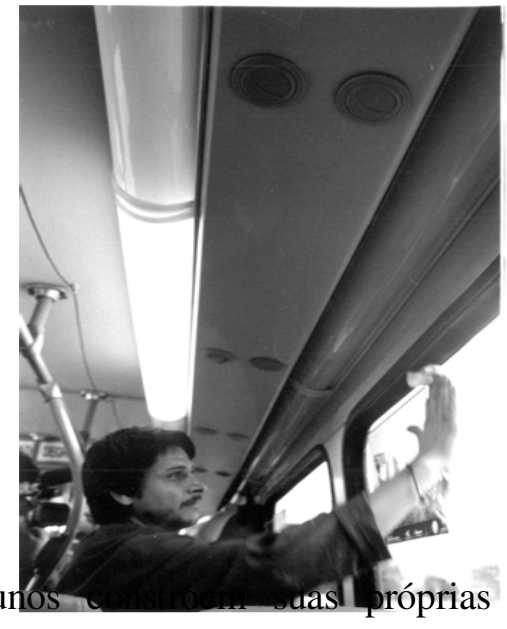

muito simples. O nome da técnica significa buraco de alfinete em inglês, referência ao minúsculo furo, único ponto que permite a entrada de luz num recipiente totalmente vedado, projetando a imagem externa em seu interior, de cabeça para baixo e espelhada. O Grupo Lata Mágica ministra oficinas de fotografia, levando o conhecimento da técnica pinhole para os seus alunos. Nas oficinas, os

transformando sucata em artefatos de construção de imagens. A fotografia, associada a uma mágica aparição de imagens, acaba sendo desmistificada como um fenômeno natural e possível graças a uma combinação de aspectos físicos e químicos. Através da imagem, temos a chance do re-conhecimento do espaço e do auto- conhecimento, já que o registro fotográfico nos oferece um tempo indefinido para nos demorarmos sobre seu espaço recortado e seu instante congelado. Para os participantes, a fotografia se transforma em uma técnica para construção de olhares sobre a realidade do cotidiano. Conforme Bourdieu, "a tradição neo-kantiana trata os diferentes universos simbólicos como instrumentos de conhecimento e de construção do mundo dos objetos, como formas simbólicas, reconhecendo como nota Marx, o aspecto ativo do conhecimento" (BOURDIEU, 1998, p. 8).

O trabalho, freqüentemente, é desenvolvido com crianças de comunidades da periferia de Porto Alegre que não possuem muitos retratos seus ou de suas famílias. Portanto, a proposta de fotografar com uma câmera construída artesanalmente, empregando materiais baratos, atrai muitos participantes. Nas oficinas do Grupo Lata Mágica, os alunos constroem suas próprias câmeras fotográficas a partir de latas vazias de leite em pó, transformando sucata em artefatos de construção de imagens.

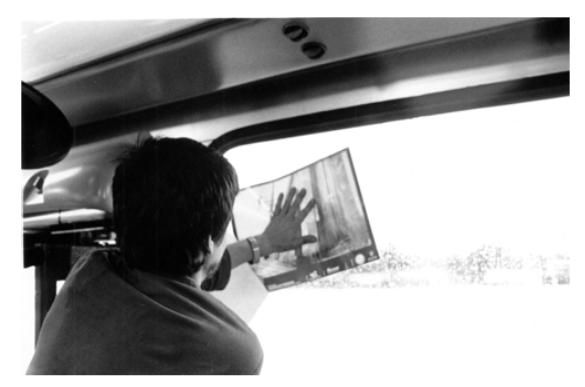

Eles participam de um processo que envolve desde a construção da câmera até a obtenção da imagem fotográfica como produto final, depois de passar pelas etapas de revelação e cópia em laboratório fotográfico preto e branco.

Após três anos trabalhando com o ensino da fotografia pinhole como uma forma de acesso a uma produção simbólica, o grupo parte para uma reflexão sobre os seus alunos como 
consumidores de fotografias. Através das oficinas, percebia-se que eram poucos os alunos de classe popular que costumavam ir a galerias de arte para a contemplação de exposições fotográficas. Porto Alegre já possuía uma relação entre arte e transporte público, devido ao projeto Poemas nos Ônibus que há mais de dez anos imprime poesias em adesivos e os colam nas janelas laterais no interior dos coletivos. O Olhar Passageiro torna-se, então, a versão fotográfica da idéia contendo, ao invés de fotografias obtidas com câmeras convencionais, as fotografias pinhole feitas em câmeras utilizando latas metálicas de panetone e papel fotográfico preto e branco $18 \times 24 \mathrm{~cm}$ como negativo. O projeto é, assim, formatado para a confecção de um conjunto de 25 imagens sobre a cidade de Porto Alegre distribuídas nos 1.600 ônibus que compõem a frota da capital em que circula a média de 1,2 milhão de pessoas por dia ${ }^{1}$.

Ao pensar em um público que, como consumidores de imagens fotográficas, tem como fonte quase que, exclusivamente, a imprensa, deve-se considerar a definição de Pierre Bourdieu para o poder simbólico como um "poder invisível que só pode ser exercido com a cumplicidade daqueles que não querem saber que lhe estão sujeitos ou mesmo que o exercem" (1998, p. 7 e 8). Assim, as produções simbólicas, nesse caso fotográficas, são relacionadas com os interesses da classe dominante por expressarem ideologias que servem a interesses particulares, das grandes empresas jornalísticas, como se fossem interesses universais. Segundo Arlindo Machado em uma obra referencial para o campo da fotografia “A Ilusão Epecular", essa expressão de um poder simbólico pode ser percebida a partir da ênfase no referente fotográfico que estabelece um estatuto de reflexo da realidade para a imagem fotográfica. A justificativa para essa postura estaria no discurso de uma ideologia dominante que apresenta um "determinado modo de apropriação do mundo como o único possível” (MACHADO, 1984, p. 40). A realidade de uma fotografia não pode ser encontrada no seu referencial ou em nenhum elemento para além dela própria, que como produto humano, carrega consigo a sua realidade. Pensando em apresentar uma concepção diferenciada à população de imagens da sua própria cidade, o projeto O Olhar passageiro propôs ao público que se pense como um consumidor de imagens "não-convencionais", inclusive na ideologia que carregam referindo-se a um contexto específico de concepção e produção.

\footnotetext{
${ }^{1}$ Dados fornecidos pela EPTC em junho de 2002, época de produção do projeto O Olhar Passageiro inscrito no Fumproarte/SMC/PMPA no segundo edital daquele ano.
} 

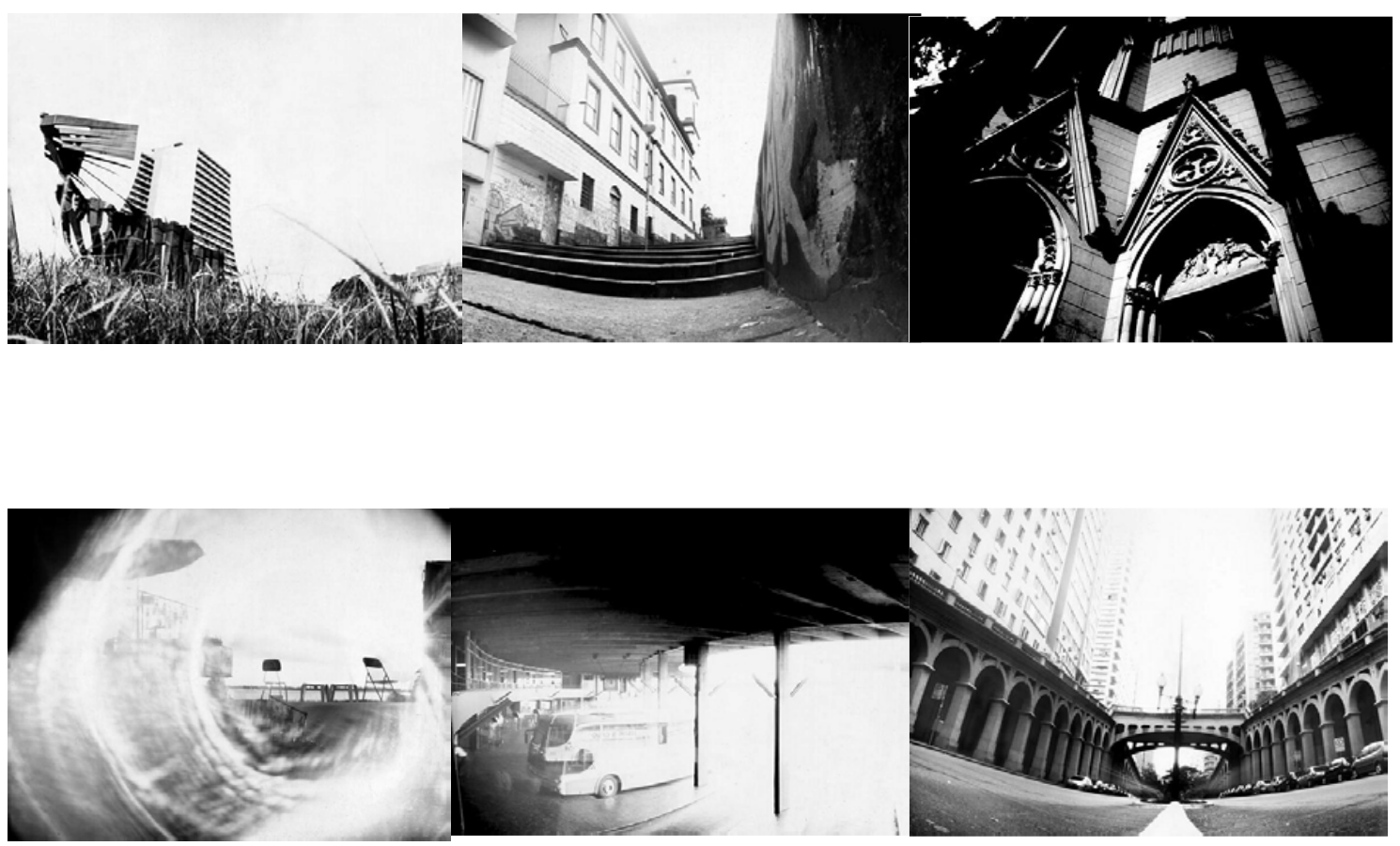

\section{Uma Proposta de Intervenção Urbana e Financiamento Público a Produções Artísticas em Porto Alegre}

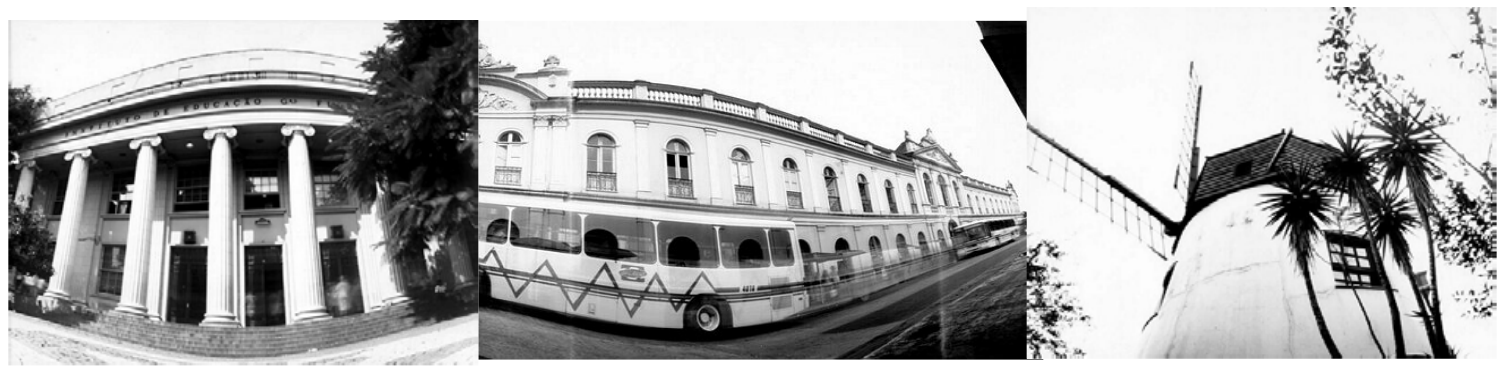

A viabilidade de execução de um projeto desse porte depende de financiamentos e patrocínio para além do "campo de produção" (BOURDIEU, 1998, p.12) artístico, entrando em um estágio de negociação que possibilite não comprometer a intenção original proposta como produto cultural. Como realizar um trabalho de qualidade técnica que requer investimento de fôlego, principalmente, quando se trata de um material gráfico inovador, envolvendo impressão fotográfica em um suporte de vinil adesivo? A opção, no caso de O Olhar Passageiro, foi inscrever o projeto no Fumproarte - Fundo Municipal de Apoio à Produção Artística e Cultural de Porto Alegre (criado 
pela Lei 7.328/93 e regulamentado pelo Decreto $10.867 / 93)^{2}$. O referido Fundo é um importante mecanismo para viabilizar a produção cultural da cidade de Porto Alegre, prestando apoio financeiro em até $80 \%$ do custo de projetos de natureza artística. Implantado em janeiro de 1994, com a abertura do primeiro edital, vem financiando projetos nas áreas de artes cênicas, dança, artes visuais, cinema, vídeo, fotografia, música, literatura, memória cultural, artesanato e folclore. Abrem-se dois editais ao ano e os interessados entregam seus projetos de acordo com um formulário padrão de apresentação. As propostas são analisadas, primeiramente, pelo Comitê Assessor, formado por cinco funcionários designados pela Secretaria Municipal da Cultura, responsável pela avaliação formal, considerando os projetos classificados ou desclassificados. Os projetos classificados são avaliados e aprovados através Comissão de Avaliação e Seleção (CAS) que considera o mérito, segundo critérios de clareza e coerência, retorno de interesse público, previsão de custos, criatividade, importância para Porto Alegre. A CAS é composta por representantes da Administração Municipal e das entidades representantes do setor artístico-cultural.

Pode-se perceber a importância do Fumproarte, como financiador do campo artístico em Porto Alegre, pelo aumento considerável do número de projetos a cada edital; de 42 inscritos no primeiro edital de 1994 a 166 inscritos no primeiro edital de $2003^{3}$. Iniciativas que não encontrariam outros tipos de patrocínio por serem "pouco vendáveis" acabam recorrendo a essa verba municipal. Como, por exemplo, ocorre com projetos de jovens artistas saídos das oficinas de Descentralização da Cultura, projeto da SMC que pretende levar o fazer artístico a regiões do orçamento participativo da cidade de Porto Alegre. Muitas vezes, artistas locais consagrados também investem no Fumproarte como uma forma de lançarem seus cds, fato recorrente entre os músicos locais. A CAS nas reuniões de avaliação abertas ao público considera esse tipo de questão, mas não decide baseando-se só nas condições do projeto conseguir ser realizado por outros meios de captação de recursos.

Outra característica marcante do processo de seleção deve-se aos pareceres feitos pela CAS, a partir da escolha de três relatores por cada projeto que apresentam suas considerações ao restante da comissão, portanto a análise de um mesmo projeto pode receber avaliações bem diversas entre si. Deve-se salientar que um dos itens de

2 Informações sobre o funcionamento do Fumproarte consultadas no site da SMC www.portoalegre.rs.gov.br/cultura/fumproarte. 
avaliação do mérito dos projetos candidatos ao recurso do Fumproarte é a importância para Porto Alegre. Assim, pode-se pensar em um tipo de projeto que encontraria um aspecto positivo ao seu favor que é a preocupação em vincular o projeto artístico à cidade. As propostas de inclusão da população no fazer artístico e de descentralização dos eventos culturais (em conformidade com projeto já citado da PMPA) também estão de acordo com a linha adotada pela Secretaria Municipal da Cultura, mesmo que implicitamente.

O Olhar Passageiro, agindo enquanto instrumento de democratização de acesso a uma manifestação artística e como agente de descentralização das atividades culturais, levando a bairros periféricos e menos favorecidos economicamente a arte fotográfica, apresenta-se em conformidade com as perspectivas de inclusão social como política pública para a área da Cultura nesta época da chamada administração popular do PT na cidade (1989 - 2004). O projeto, aprovado no segundo edital do ano de 2002, pretende lançar um novo olhar sobre Porto Alegre, mostrar ângulos desconhecidos e novos lugares a serem explorados. Pois, a fotografia possui a capacidade de re-significar o ambiente. Ao recriar um cenário, transpondo-o para as duas dimensões do registro fotográfico, apresenta ao observador uma nova visão sobre um espaço já conhecido. Na verdade, o projeto prevê a discussão sobre os espaços públicos fotografados e colocados nos ônibus, tanto sobre as novas edificações como a Estação Carlos Gomes como o Chalé da Praça XV, antigo símbolo da cidade. Ana Lúcia Meira (2004), cujo livro também foi financiado pelo Fumproarte na área de Memória Cultural, salienta que existe um tipo de demanda de preservação em relação ao patrimônio vindo da comunidade organizada e cita o Fumproarte como um dos responsáveis por uma consciência de "pertencimento" da população resultante das discussões sobre a cidade.

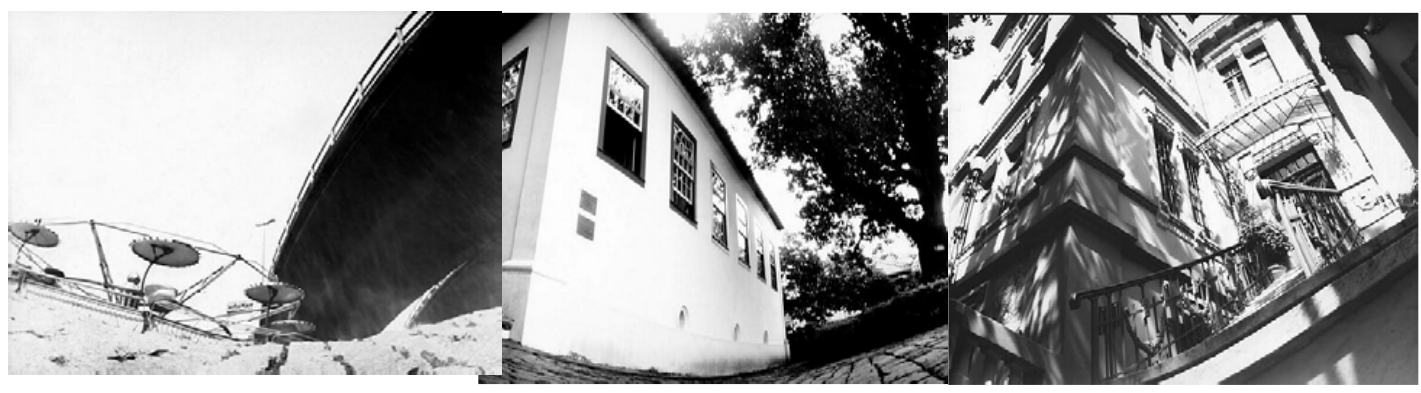

\footnotetext{
${ }^{3}$ Números retirados do Catálogo Fumproarte 10 anos.
} 


\section{Intervenção Urbana e Apropriação do Espaço Público}

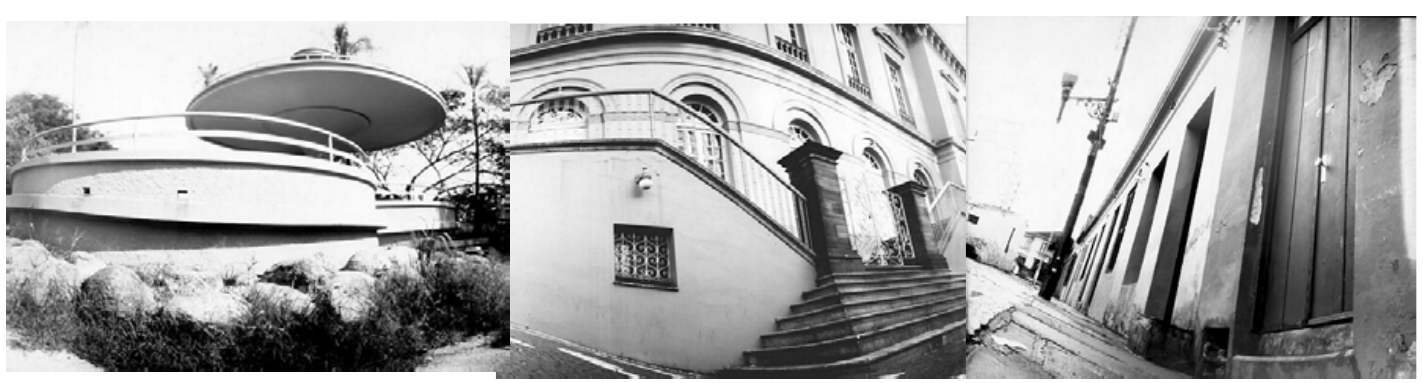

A partir das fotografias coladas nas janelas internas dos ônibus de Porto Alegre, pode-se pensar em uma política de apropriação do espaço público. A cidade retratada e devolvida, como imagens elaboradas, ao olhar da própria população local. A reflexão sobre as fotografias apresentadas pode favorecer a construção social do espaço público, assim como a reflexão sobre a apropriação desse mesmo espaço, na medida em que destaca a existência de certos lugares até mesmo esquecidos por essa população como a Escadaria da Rua João Manoel que liga a Fernando Machado à Duque de Caxias em Porto Alegre. Antônio Arantes (2000) coloca a questão da cidadania como um sentimento de "pertencer a" e o Olhar Passageiro traz a cidade das pessoas para próximo delas, para um momento de se pensar como parte integrante do itinerário urbano em uma simples viagem de ônibus. A fotografia de dentro do ônibus pretende conduzir o olhar para a cidade que "passa" atrás do vidro. Uma cobradora da linha T5 deixa isso claro ao se referir à imagem da Igreja Santa Teresinha como a sua fotografia preferida, dentro do projeto $\mathrm{O}$ Olhar passageiro, porque o ônibus em que trabalha passa em frente à referida igreja e, afetivamente, se tornou a mais significativa entre o conjunto de adesivos.

Sandra Pesavento define o conceito de "leitores especiais da cidade" (apud MEIRA, 2004, p. 32) como aqueles observadores privilegiados do espaço urbano, por exemplo, os fotógrafos, e destaca a participação desses em Porto Alegre para a preservação do patrimônio edificado. Isso pode ocorrer no momento em que o fotógrafo traz a cidade para as duas dimensões da fotografia como um instrumento de valorização desses espaços, a "vida materialmente construída na sua espacialidade" (MEIRA, 2004, p. 34) alimentada pela preservação da paisagem urbana.

A paisagem urbana de Porto Alegre configura as práticas sociais que nela ocorrem, assim como o Muro da Mauá afasta a cidade do rio, a Usina do Gasômetro reaproxima ao levar a população para orla do Guaíba aos domingos. A preservação do 
patrimônio deve ser pensada como uma prática social, segundo Arantes, e essa prática configura o espaço público. O Olhar Passageiro é um entre vários acontecimentos culturais que ao propor uma nova relação com a cidade pretende estimular uma apropriação do espaço público de forma mais intensa pela sua população.

A paisagem edificada torna-se um elemento destacado para a formação das práticas sociais. Pois, ancoram lembranças em que são inseparáveis dos eventos que ali ocorreram (ARANTES, 2000, p. 21). A população provavelmente esquecerá que as fotografias estiveram nos ônibus, mas os lugares, na medida em que são incorporados ao seu imaginário, continuarão a construir a imagem da cidade para essa população. Sendo a configuração de um "imaginário social”, segundo Meira, e é através desse imaginário que a sociedade constrói uma imagem de si. O Olhar Passageiro pretende agir na preservação de um patrimônio para Porto Alegre que é o próprio fortalecimento da configuração de um imaginário sobre a cidade.

Ao propor uma nova relação com o espaço público, a partir do imaginário da cidade, torna-se necessário conhecer melhor essa mediação simbólica através da qual espaço e tempo participam da estruturação da experiência social. Podemos analisar essa mediação, imaginário/espaço público, "ao inserir a cidade no corpo das motivações simbólicas do homem ocidental" (2001 [1], p. 2), conforme propõe Ana Luiza Carvalho da Rocha. Pode-se analisar a experiência do Olhar Passageiro tendo como ponto de partida a cidade, inspiradora de uma prática do grupo para além desse trabalho. Pois, ao ensinar a técnica pinhole, em suas oficinas, o grupo propõe aos alunos um novo conceito sobre o espaço em que vivem ao se apropriarem dele através de uma linguagem fotográfica diferenciada.

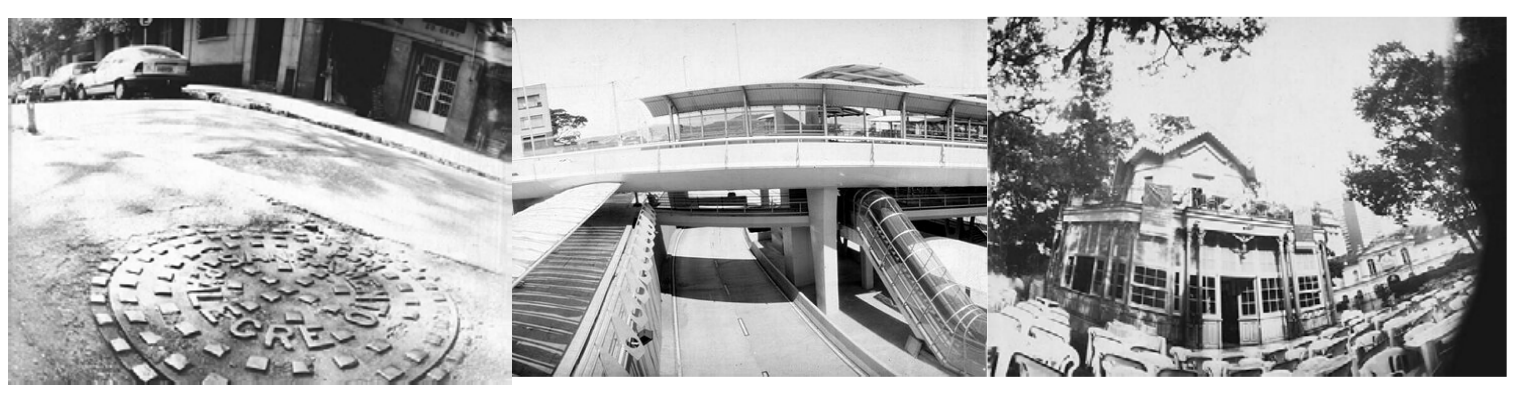


O Olhar Passageiro e a Cidade

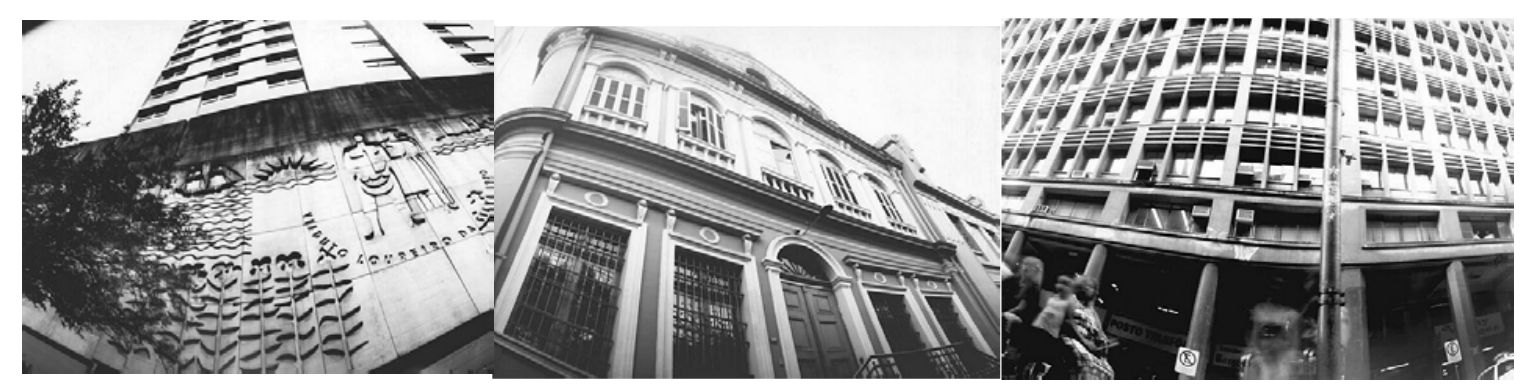

A Cidade "ilustra a forma como o pensamento do homem ocidental se traveste de um esquema cultural urbano para projetar os símbolos através dos quais organiza o mundo" (ROCHA, 2001 [1], p. 5). O Olhar Passageiro ilustra a cidade com imagens que configuram um outro tipo de pensamento sobre a mesma. A técnica pinhole carrega elementos próprios decorrentes da linguagem utilizada porque ao ser feita com uma lata, ela distorce a imagem conforme a curvatura do recipiente utilizado como câmera. A ausência de lentes causa um efeito grande-angular, que se traduz no destaque dado ao primeiro plano da imagem, e o tempo de exposição, para se obter uma imagem, aumenta significativamente, levando de trinta segundos a meia hora para uma imagem externa em dia ensolarado. Esses elementos conformam uma imagem surpreendente ao apresentar a cidade, como, por exemplo, a fotografia do Instituto de Educação que oferece um prédio distorcido em forma de um olho quando, na realidade, trata-se de um prédio de linhas clássicas. Portanto, não se pode negar o convite a pensar sobre essa imagem que não se apresenta como um espelho da realidade, pelo contrário, se afirma como uma representação concebida e construída pelo homem. Pode-se analisar essa questão da representação, que se diferencia do registro fotográfico espalhado pelas cidades em cartazes de publicidades, outdoors, etc, dentro da perspectiva do póscolonialismo, representa aqui por Homi Bhabha (2001), em que não se pode negar a heterogeneidade da nação moderna, assim vivências múltiplas representam-se de formas variadas. A nação moderna apresenta uma "forma de vida mais híbrida na articulação de diferenças e identificações culturais do que pode ser representado em qualquer estruturação hierárquica ou binária do antagonismo social” (2001, p. 199).

Considera-se, aqui, a cidade urbano-industrial moderna como expressão do estadonação, proposto por Bhabha, uma nação como articulação de heterogeneidades. A cidade urbano-industrial dramatiza o estado-nação por se configurar em uma co- existência "de grupos sociais, culturas, línguas, religiões, idades, atividades humanas diversificadas" (ROCHA, 2001 [1], p. 4). A cidade é vista, conforme Rocha, como uma "forma de 
organização espaço-temporal policêntrica e polissêmica, espaço de produção e expressão do múltiplo" (2001 [1], p. 4).

O Olhar Passageiro como intervenção urbana na cidade de Porto Alegre expressa uma construção de sentido para uma estética do urbano que não é aquela esperada. A fotografia pinhole re-significa lugares patrimoniais de Porto Alegre ao distorcer suas imagens pré-concebidas por seus habitantes e isolando-as do contexto em que estão inseridas na cidade, mas as mantém no espaço urbano ao circularem nos ônibus da capital. Permite o contraponto entre a imagem fixa na janela do ônibus e o deslocamento do mesmo em relação à paisagem para além do vidro. Uma nova representação de cidade se estabelece na troca simbólica entre as imagens do grupo Lata Mágica e as imagens do espaço que constituem cada passageiro de ônibus.

O espaço do povo-nação possui uma temporalidade de representação entre formações culturais e processos sociais sem lógica causal centrada, conforme Bhabha (2001, p. 201), e esse espaço requer uma escrita que restitua a temporalidade ambivalente que o constitui. As informações "do" e "sobre" o espaço urbano provêm de inúmeras fontes para os seus habitantes devido à multiplicidade da vida urbana nas cidades modernas. Homi Bhabha apresenta uma análise sobre a questão do estado- nação a partir da sua construção como narrativa e considera que "a força narrativa e psicológica que a nacionalidade apresenta na produção cultural e na projeção política é o efeito da ambivalência da "nação" como estratégia narrativa" (2001, p. 201).

A nação, se encarada como narração, exige sua representação como um processo temporal, pois para escrever a história da nação é preciso articular a ambivalência que embasa o tempo da modernidade e que constitui o seu tempo como um tempo disjuntivo

(BHABHA, 2001, p. 201). É necessário um tempo de escrita particular que contemple os fragmentos e retalhos de significação cultural que articulam o estatuto de modernidade das cidades urbano-industriais. Assim, a experiência de apresentar e representar a cidade através de imagens pinhole, também, oferece um outro tempo ao espectador/habitante. O tempo necessário para se obter uma pinhole é de, no mínimo, trinta segundos, contrastando com os instantes fotográficos da linguagem convencional. $\mathrm{Na}$ verdade, as imagens captadas traduzem momentos da cidade ao contrário de instantes. Uma cena inteira transcorre diante da câmera fotográfica para depois aparecer em uma única imagem. A fotografia do Mercado Público pode traduzir essa temporalidade através de um ônibus captado durante sua chegada ou partida, não se sabe, do terminal. Podemos ver, através da sua estrutura, as portas do mercado, como se o ônibus fosse transparente. Uma 
temporalidade diversa se apresenta ao ser captada uma imagem sem congelamento, um tempo que se assemelha ao das cidades modernas ao contemplar a multiplicidade de eventos.

Arantes cita Bhabha (2000, p. 139), ao se perguntar até que ponto é possível acomodar a diversidade cultural no interior de uma mesma "moldura política"? A mesma pergunta pode ser feita ao tratar das representações da cidade moderna. Como acomodar a diversidade cultural no instante de uma fotografia? A solução adotada, na experiência do Olhar Passageiro, foi deixar os momentos transcorrerem diante da câmera fotográfica produzida a partir de uma lata que não foi concebida, em momento algum, para se transformar em aparato técnico de produção de imagens. Uma transposição de um tempo fotográfico diferente a partir de uma câmera produzida de um artefato humano que nem mesmo seus produtores imaginariam quais as possibilidades de apropriação possíveis desse objeto.

As paisagens urbanas configuram uma "trama espacial em processo violento de destruição e de transformação devido à agitação temporal em uma era de globalização" (ROCHA, 2001 [1], p. 5), onde o debate das políticas culturais na área de preservação patrimonial deve ser intensificado na intenção de acomodar as antigas e novas temporalidades da cidade. O Olhar passageiro procura ressaltar esse cotidiano que se traduz em construções edificadas de tempos diferentes ao retratar o antigo e também o novo como o viaduto sobre a III Perimetral, construção que ainda não estava totalmente terminada na época de obtenção das imagens.

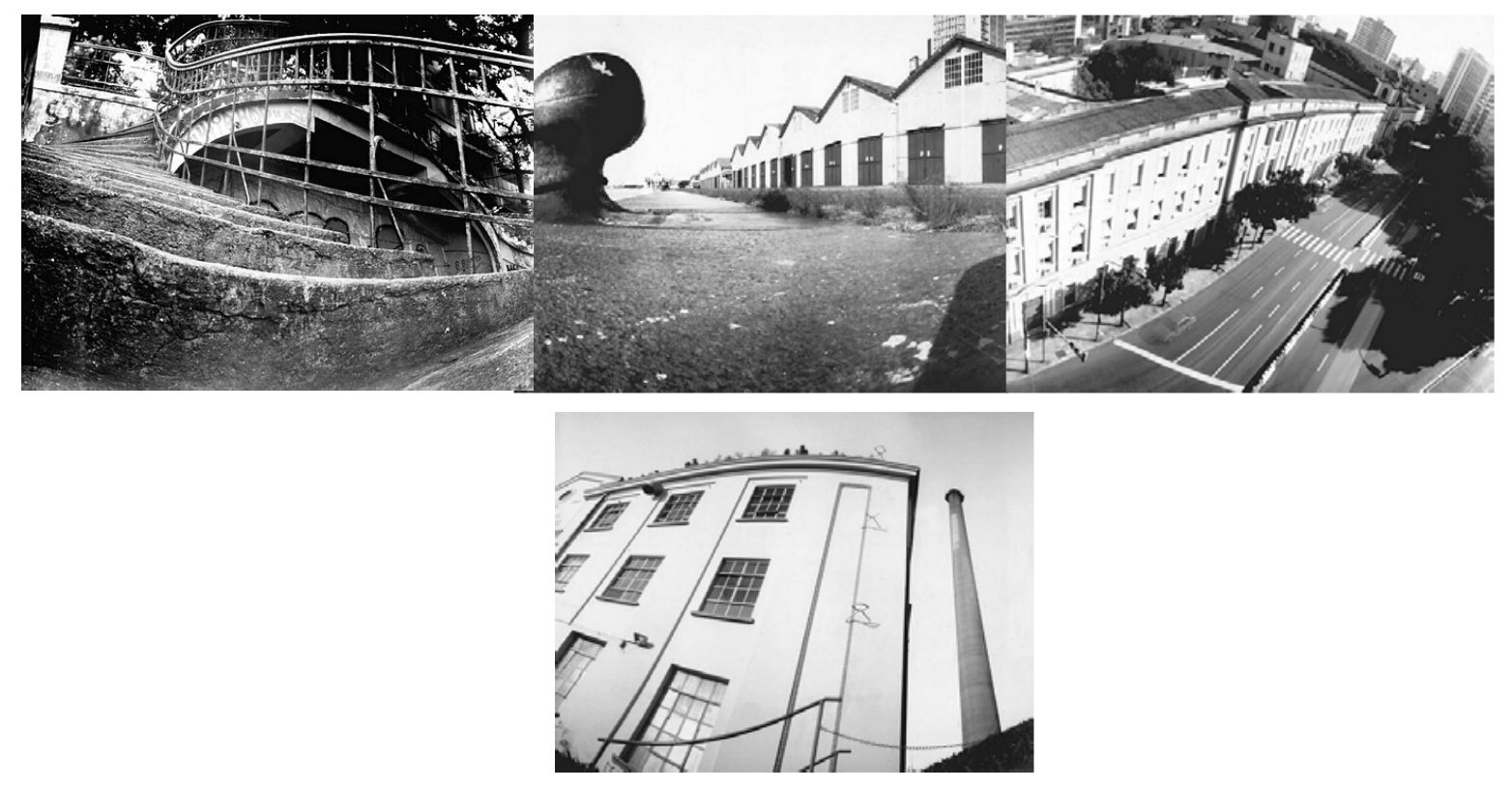




\section{REFERÊNCIAS}

ARANTES, Antônio Augusto. Paisagens Paulistanas: transformações do espaço público. Campinas, SP: Editora da Unicamp; São Paulo: Imprensa Oficial, 2000.

BHABHA, Homi K. O Local da Cultura. Belo Horizonte: Editora da UFMG, 2001. BIAZUS, Paula e DEL FRARI, Maísa. "A Fotografia como Instrumento de Conhecimento de Si e do Mundo". Trabalho apresentado durante o I Encontro Foto- Educativo: Intervenção e Pesquisa. Universidade Federal de Santa Catarina, 2004.

BOURDIEU, Pierre. O Poder Simbólico. Rio de janeiro: Bertrand Brasil, 1998. MACHADO, Arlindo. Aillusão especular: Introdução à Fotografia. São Paulo: Editora Brasiliense, 1984.

MEIRA, Ana Lúcia. O passado no futuro da cidade: políticas públicas e participação popular na preservação do patrimônio cultural de Porto Alegre. Porto Alegre: Editora da UFRGS, 2004.

RICOEUR, Paul. Tempo e Narrativa (Tomo I). Campinas: Papirus, 1994.

ROCHA, Ana Luiza Carvalho da. "Cidade como lugar do próprio e do absoluto: os dilemas de uma política de valorização de bens culturais". In: Iluminuras, Série do Banco de Imagens e Efeitos Visuais, número 31. Porto Alegre: BIEV, PPGAS/UFRGS, 2001. (1)

ROCHA, Ana Luiza Carvalho da. "As figurações de lendas e mitos históricos na construção da Cidade tropical". In: Iluminuras, Série do Banco de Imagens e Efeitos Visuais, número 34. Porto Alegre: BIEV, PPGAS/UFRGS, 2001. (2)

\section{Outras Fontes}

www. portoalegre.rs.gov.br/cultura/fumproarte 